\title{
Large scale gas injection test (Lasgit): Results from two gas injection tests
}

\author{
R.J.Cuss ${ }^{1}$, J.F. Harrington ${ }^{1}$, D.J. Noy ${ }^{1}$, A. Wikman ${ }^{2}$, P. Sellin ${ }^{2}$ \\ 1. British Geological Survey, Keyworth, Nottingham, NG12 5GG, UK (rjcu@bgs.ac.uk) \\ 2. SKB, Stockholm, Sweden (patrik.sellin@skb.se)
}

\begin{abstract}
This paper describes the initial results from a large scale gas injection test (Lasgit) performed at the Äspö Hard Rock Laboratory, Sweden. Lasgit is a full-scale field-scale experiment based on the Swedish KBS-3V repository concept, examining the processes controlling gas and water flow in compact buffer bentonite. The first two years of the test focused on the artificial hydration of the bentonite buffer. This was followed by a programme of hydraulic and gas injection tests which ran from day 843 to 1110. A further period of artificial hydration occurred from day 1110 to 1385 , followed by a more complex programme of gas injection testing which remains on going (day 1385+). After two years of hydration, hydraulic conductivity and specific storage values in the lower filter array were found to range from $9 \times 10^{-14}$ to $1.6 \times 10^{-13} \mathrm{~m} / \mathrm{s}$ and $5.5 \times 10^{-5}$ to $4.4 \times 10^{-4} \mathrm{~m}^{-1}$ respectively, with the injection filter FL903 yielding values of $7.5 \times 10^{-14} \mathrm{~m} / \mathrm{s}$ and $2.5 \times 10^{-5} \mathrm{~m}^{-1}$. A second set of hydraulic measurements were performed over year and a half later yielding similar values, in the range $7.8 \times 10^{-14} \mathrm{~m} / \mathrm{s}$ and $1.3 \times 10^{-13} \mathrm{~m} / \mathrm{s}$. The hydraulic conductivity of FL903 had reduced slightly to $5.3 \times 10^{-14} \mathrm{~m} / \mathrm{s}$ while specific storage had increased to $4.0 \times 10^{-5} \mathrm{~m}^{-1}$. Both datasets agree with laboratory values performed on small-scale saturated samples.

Two sets of gas injection tests were performed over a three year period. During the course of testing, gas entry pressure was found to increase from around $650 \mathrm{kPa}$ to approximately 1.3 MPa, indicative of the maturation of the clay. The sequential reduction in volumetric flow rate and lack of correlation between the rate of gas inflow and the gas pressure gradient observed during constant pressure steps prior to major gas entry, is suggestive of a reduction in gas permeability of the buffer and indicates only limited quantities of gas can be injected into the clay without interacting with the continuum stress field. Major gas entry occurs at a gas pressure close to, or slightly in excess of, the local stress state and is associated with a rapid increase in flux, linked to a series of kicks in axial and radial stress and porewater pressure. Post peak gas flux exhibits dynamic behaviour symptomatic of unstable gas flow. When gas injection is stopped, flux into the clay rapidly reduces before entering an extended period of very small flows. This is accompanied by a rapid reduction in pressure which decays to an asymptotic value close to that of the total stress locally within the deposition hole. Examination of the data shows considerable evidence for the development of a highlydynamic, tortuous network of pressure induced pathways which evolve both temporally and geospatially within the clay, opening and closing probably due to local changes in gas pressure and/or effective stress. These detailed observations do not conform to standard concepts of two-phase flow. The bentonite response to the passage of gas suggests that pathway dilation is the primary mechanism governing gas migration within the Lasgit system. The important coupling between gas, stress and porewater pressure at the repository scale is clearly evident with the data. The importance and interdependencies of this coupling will be investigated in future experiments planned at the Lasgit experimental site.
\end{abstract}

\subsection{Introduction}

In the Swedish KBS-3 disposal concept [SKB TR-09-22], copper/steel canisters containing spent nuclear fuel will be placed in large diameter disposal boreholes drilled into the floor of 
the repository tunnels. The space around each canister will be filled with pre-compacted bentonite blocks which, over time, will draw in the surrounding groundwater and swell, closing any construction gaps. Once hydrated, the bentonite will act as a low permeability diffusional barrier, severely limiting the migration of any radionuclides released from a canister after closure of the repository. While the waste canisters are expected to have a very substantial lifespan within the repository environment, it is important for purposes of performance assessment to consider the impact of groundwater penetration of one of the canisters. Under certain repository conditions, corrosion of the steel inner will lead to the formation of hydrogen gas. Radioactive decay of the waste and the radiolysis of water will produce additional gas within the container void. Depending on the rate of gas production and the rate of diffusion of gas molecules in the pores of the bentonite, it is possible a pressurised gas phase will accumulate in the void space of the canister [Horseman, 1996; Horseman et al., 1997; 1999]. Gas will then enter the bentonite when the gas pressure exceeds some critical entry pressure specific to this material. Since water penetration of the canister is a prerequisite for the generation of hydrogen gas in the buffer, the timing of gas movement in the clay might coincide with that of radionuclide release into the buffer porewater. The possibility of an interaction between gas and radionuclide migration therefore emerges as an important issue in performance assessment.

However, the quantitative treatment of gas migration in compact clays is a highly complex issue [Rodwell et al, 1999]. In recent years a number of laboratory studies of gas migration in repository buffer clays have been undertaken. These experiments have focussed on gas movement in initially saturated material [Donohew et al. 2000; Harrington and Horseman 1999; Horseman and Harrington 1994, Horseman et al. 1999, Horseman et al. 1999, Hume 1999; Ortiz et al, 1997; Tanai et al. 1997; Harrington and Horseman 2003] and in unsaturated clays [Gallé 1998; Gallé et al 1998; Gray et al 1996; Hume 1999, Tanai et al 1997], with a review of past work provided in Rodwell et al. (1999). Results from these studies indicate breakthrough pressure is strongly dependent on the degree of water saturation of the bentonite. At water saturations less than 70\% [Tanai et al. 1997] to around 80 to 90\% [Hume, 1999], clay contains an interconnected network of air voids resulting in little or no pressure threshold for gas flow. As full saturation is approached, gas entry and breakthrough pressures increase rapidly [Gray et al 1996; Hume 1999]. Horseman et al. (1999) questioned whether gas flow occurred through the original porosity of the clay or through a network of crack-like pathways which opened and closed dependant on the magnitude of the gas pressure. The view was expressed that bentonite close to full saturation is totally impermeable to gas and that conventional 2-phase flow is impossible in this material. Experiments reported by Donohew et al. [2000] suggest that a saturated clay must dilate (i.e. grow in volume) during gas entry and the initial changes in gas content are accommodated by an increase in the total volume of the clay. Although this is consistent with gas flow through a network of pressure-induced pathways, it cannot be reconciled with the more usual soil mechanics concept of desaturation by direct displacement of porewater. If all gas in the clay is accommodated by dilatancy, this raises the important question of sensitivity of the gas transport process to the boundary conditions of an experiment [Horseman et al., 1999].

While these studies have improved our understanding of the gas-buffer system, recent laboratory work [Horseman et al. 2004] has highlighted a number of significant uncertainties, notably the sensitivity of the gas migration process to experimental boundary conditions and possible scale-dependency of the measured responses. This issue is best addressed by undertaking a large scale gas injection test or "Lasgit" [Sellin and Harrington, 2005].

Lasgit is a full-scale demonstration experiment operated by SKB at the Äspö Hard Rock Laboratory at a depth of $420 \mathrm{~m}$. The objective of Lasgit is to provide quantitative data to 
improve process understanding and test/validate modelling approaches which might be used in performance assessment.

\subsection{Data reduction}

The governing equation for flow in variably saturated porous media can be derived from Darcy's Law and the conservation of mass [Huyakorn and Pinder, 1983]

$$
\nabla \bullet\left[K_{r} K \nabla(\psi+z)\right]+q=\left(\phi \frac{\partial S_{w}}{\partial \psi}+S_{w} S_{s}\right) \frac{\partial \psi}{\partial t}
$$

where $K_{r}$ is the relative permeability, $K$ is the saturated hydraulic conductivity, $\psi$ is the pressure head, $z$ is the elevation, $q$ is a fluid source rate, $\phi$ is the porosity, $S_{w}$ is the water saturation, and $S_{s}$ is the specific storage. The pressure head, $\psi$, is positive in the saturated region and negative in the unsaturated region. Equation (1) is highly non-linear because both the relative permeability and the water saturation are functions of the pressure head. A number of such functions are available in the literature but the most commonly used are those due to van Genuchten [1980]

$$
\begin{aligned}
& S_{w}(\psi)=S_{r}+\left(1-S_{r}\right)\left[1+(-\alpha \psi)^{n}\right]^{-m} \\
& K_{r}(\psi)=\sqrt{S_{e}}\left[1-\left(1-S_{e}^{1 / m}\right)^{m}\right]^{2}
\end{aligned}
$$

where $m$ and $S_{e}$ are given by :-

$$
\begin{aligned}
& m=1-1 / n \\
& S_{e}=\frac{S_{w}-S_{r}}{1-S_{r}}
\end{aligned}
$$

and $S_{r}$ is the residual water saturation. The parameters $\alpha, n$, and $S_{r}$ are obtained by fitting these functions to experimental data. Equation (1) can be applied to the saturated region by setting $S_{w}$ and $K_{r}$ equal to 1 for all positive values of pressure head, $\psi$. The solution to equation (1) can be obtained by applying standard finite element techniques and supplying appropriate initial and boundary conditions [Huyakorn and Pinder, 1983]. Picard iteration can be used to resolve the non-linearities.

\subsection{Experimental concept}

The aim of the Lasgit experiment is to perform a series of gas injection tests in a full-scale KBS-3 deposition hole. The objective of the experimental programme is to provide quantitative data to improve process understanding and test/validate modelling approaches used in repository performance assessment. Specific objectives include: perform and interpret a series of large-scale gas injection tests based on the KBS-3 repository design concept; examine issues relating to up-scaling and its effect on gas movement and buffer performance; provide information on the processes governing gas migration; and provide high-quality test data to test/validate modelling approaches. In essence, the Lasgit experiment consists of three operational phases; an installation phase, a hydration phase and a gas injection phase. The installation phase was undertaken from 2003 to early 2005 and consisted of the design, 
construction and emplacement of the infrastructure necessary to perform the Lasgit experiment [Cuss et al. 2010]. The initial hydration phase began on the $1^{\text {st }}$ February 2005 with the closure of the deposition hole. The primary aim of this phase of the experiment is to fully saturate and equilibrate the buffer. The saturation and equilibration of the bentonite is monitored by measuring pore pressure, total pressure and suction at both the buffer/rock interface and key locations within individual clay blocks. The hydration phase provides an additional set of data for (T)HM modelling of water uptake in a bentonite buffer. When the buffer is considered to be fully hydrated, the main gas injection phase will start. A series of detailed gas injection tests will be performed and the processes and mechanisms governing gas flow in the bentonite will be examined. However, given the length of time required to equilibrate such a large quantity of clay, it was decided to augment the data by performing a series of preliminary gas and hydraulic measurements, undertaken at regular intervals in order to examine the effect of buffer maturation on the hydraulic and gas transport parameters of the buffer.

\subsection{Experimental geometry}

The Lasgit experiment was commissioned in deposition hole No. DA3147G01 - the first emplacement borehole to be drilled at the Äspö URL. The deposition hole has a length of $8.5 \mathrm{~m}$ and a diameter of around $1.75 \mathrm{~m}$. A full-scale KBS-3 canister has been modified for the Lasgit experiment with twelve circular filters of varying dimensions located on its surface in three separate arrays (Figures 1 and 2), to provide point sources for gas injection mimicking potential canister defects. These filters can also be used to inject water during the hydration stage to help locally saturate the buffer around each test filter. The canister is surrounded by specially manufactured pre-compacted bentonite blocks, all of which had initial water saturations in excess of 95\% [Cuss et al, 2010].

The deposition hole, buffer and canister are equipped with instrumentation to measure the total stress, porewater pressure and relative humidity in 32, 26 and 7 positions respectively (Figure 1). Additional instrumentation continually monitors variations in temperature, relative displacement of the lid and the restraining forces on the rock anchors. The emplacement hole has been capped by a conical concrete plug retained by a reinforced SS2172 carbon steel lid capable of withstanding over $5000 \mathrm{kN}$ force. Figure 3 shows a photograph of the test site following the installation stage. The state-of-the-art experimental monitoring and control systems for Lasgit are housed in the "Gas Laboratory" which is a selfcontained temperature controlled unit designed and assembled by BGS within a modified shipping container. A customised graphical interface based on National Instruments LabVIEW $^{\mathrm{TM}}$ software enables remote control and monitoring of the test to be undertaken by project staff from any internet connected PC around the world.

\subsection{Geological description of deposition hole DA3147G01}

Deposition hole DA3147G01 was constructed in 1999 using a specially made vertically drilling Robbins tunnel boring machine (TBM). Soon after completion the hole was geologically mapped in detail from a cage hooked up to a lift. The result of the detailed mapping of the deposition hole is shown in Figure 4. As such, four major rock types have been distinguished in the deposition hole; Äspö diorite, greenstone, fine-grained granite, and pegmatite. Besides some specific features (listed below) the rock types resemble those that have been described for the walls and roof of the assembly hall [Cuss et al, 2010]:

- Äspö diorite. In the deposition hole the Äspö diorite is mainly of the feldspar megacryst bearing type. The colour is grey-dark grey sometimes slightly reddish grey. It constitutes about $85 \%$ of the hole-surfaces (wall and bottom) and is spread throughout the hole. 
- Greenstone. The "greenstone" that was found in the deposition hole is fine-grained and black. It occurs as xenoliths scattered in the Äspö diorite. The patches of "greenstone" (7\% of the hole-surfaces) may sometimes include minor amounts of the Äspö diorite itself and pegmatite.

- Fine-grained granite. Two greyish red to pinkish red rock varieties assembled under the generic name fine-grained granite constitute $5 \%$ of the hole-surfaces. They appear in approximately equal amounts mainly in the lower part of the hole. One type is medium grained and may be regarded as a hybrid between fine-grained granite and Äspö diorite and occurs often as small "lenses” in the Äspö diorite proper. The other, fine- to mediumgrained type and a more typical representative of the fine-grained grained granite forms 0.05 - $0.1 \mathrm{~m}$ wide veins. It occurs also as fracture filling.

- Pegmatite. It constitutes only $3 \%$ of the mapped surfaces. It appears as a light red approximately $0.1 \mathrm{~m}$ wide vein in the lower part of the hole.

The position of fractures on the wall and base of the deposition hole are shown in Figure 4. The fracture orientations can be presented in Schmidt net and joint rosette diagrams which show two major fracture sets [Cuss et al, 2010]. One is rather steeply dipping and has a mean orientation of approximately $120^{\circ} / 75^{\circ}$ (strike/dip right) while the other is gently dipping with a mean orientation of $195^{\circ} / 20^{\circ}$. Most of the fractures (57\%) in the deposition hole were found to be natural, probably formerly healed and tight fractures, that are now more or less re-opened due to the drilling of the hole. Twenty-nine percent were classed as healed/tight fractures and 14\% were classified as 'open' natural fractures. It is anticipated that these features will act as 'sinks' during the main gas injection phase of testing.

Prior to the emplacement of the canister and clay a series of hydrogeological tests were performed within the deposition hole and accompanying rock anchors [Cuss et al. 2010]. These included: measurement of water inflow rates to the deposition hole, yielding a value of around 266 litres/day (correcting for evaporation); pressure build-up tests in the rock anchors and neighbouring pilot hole, yielding transmissivities in the range $9 \times 10^{-12}$ to $3 \times 10^{-9} \mathrm{~m}^{2} / \mathrm{s}$; gas pressurisation of the anchor holes to map the discharge of gas within the deposition hole; hydraulic testing of the engineered damaged zone (EDZ) on the surface of the rock wall. Cuss et al. [2010] provide a detailed description of the results from these tests.

\subsection{Results}

The deposition hole was closed on the $1^{\text {st }}$ February 2005 signifying the start of the first hydration phase. Artificial hydration began a few months later on the $18^{\text {th }}$ May 2005 after 106 days of testing and was suspended at day 843 to allow the first set of preliminary measurements to be made. Results from the initial hydration phase are discussed in detail in Cuss et al [2010]. However, by the time the hydration phase had been suspended, pressures within the deposition hole and bentonite had increased substantially, with the average axial stress (monitored at separate locations throughout the clay) around $5.1 \mathrm{MPa}$, the average radial stress (measured at the rock wall) close to $4.15 \mathrm{MPa}$, the average total stress acting on the canister around 4.5 $\mathrm{MPa}$, the average porewater pressure (measured at the rock wall) approximately $1.75 \mathrm{MPa}$ and the average porewater pressure in the bentonite around $0.32 \mathrm{MPa}$. While data from the psychrometers (identified by the letter $\mathrm{W}$ on Figure 1) and porewater pressure sensors showed sections of the clay remained in suction/hydraulic disequilibrium, it was decided to examine the evolution of gas transport behaviour within the buffer during the hydration phase by performing a number of preliminary gas tests. The filter selected for this task was FL903 located in the lower array (Figure 3) as data indicated this section of the clay was more mature than the overlying material. To minimise the possible 
impact of gas injection on the continued hydration of the clay, relatively small volumes of gas were used during each gas test.

\subsection{Phase 1 (day 0 to 1110)}

Phase 1 of the Lasgit experiment ran from the start of the test to day 1110 and was comprised of three components, an initial hydration stage, baseline hydraulic measurements and a smallscale gas injection test.

\subsubsection{Baseline hydraulic tests}

A preliminary set of baseline hydraulic measurements were started on the $25^{\text {th }}$ May 2007 with the isolation of the lower canister filters FL901 to FL904 (Figure 3) while artificial hydration continued through all other canister filters and filter mats. This phase of testing lasted from day 843 to day 917. The pressure responses at filters FL901 to FL904 are shown in Figure 5, and the flow rates monitored during the constant head test performed in FL903 are presented in Figure 6. In order to obtain estimates of the hydraulic conductivity and specific storage it was necessary to develop a model of the flow processes which accounted for the initial saturation state of the clay. Preliminary modelling of the hydraulic tests was performed using a 2D axisymmetric variably saturated finite element porewater flow model. Hydraulic conductivity and specific storage values were found to range from $9 \times 10^{-14}$ to $1.6 \times 10^{-13} \mathrm{~m} / \mathrm{s}$ and $5.5 \times 10^{-5}$ to $4.4 \times 10^{-4} \mathrm{~m}^{-1}$ respectively. Filter FL903 was modelled with a hydraulic conductivity of $7.5 \times 10^{-14} \mathrm{~m} / \mathrm{s}$ and a specific storage of $2.5 \times 10^{-5} \mathrm{~m}^{-1}$. These values are well below the design specifications for the KBS-3V reference concept which stipulate a hydraulic conductivity of $10^{-12} \mathrm{~m} / \mathrm{s}$ or less [SKB TR-09-22]. The values are also within the range reported by Harrington \& Horseman [2003] who quote measured hydraulic conductivities between $3.9 \times 10^{-15}$ and $9.28 \times 10^{-14} \mathrm{~m} / \mathrm{s}$.

\subsubsection{Initial gas injection tests}

Prior to the start of gas testing all tubework to and from filter FL903 was gas flushed with helium to remove the previous hydraulic permeant. Gas testing then began on day 917 with the introduction of an initial gas volume of around $1.26 \times 10^{-3} \mathrm{~m}^{3}$ into the test system. This was slowly compressed by pumping water into an external reservoir which gradually raised the gas pressure in FL903, Figure 7 (A). Inspection of the graph indicates that during the first gas pressurisation event (days 917 to 930 ), the measured pressure begins to depart from the predicted pressure derived from the ideal gas ${ }^{1}$. This occurs at around day 924. As gas pressure continues to increase the departure in predicted versus measured gas pressure continues and is of sufficient magnitude to be indicative of gas penetration of the buffer. Analysis of the data suggests that gas flow into the buffer occurs at a pressure of about $0.65 \mathrm{MPa}$. This is much lower than the anticipated gas entry pressure for a saturated intact bentonite [Harrington and Horseman, 2003]. Given the incomplete hydration state of the buffer and the heterogeneous nature of the stress field within the clay, it seems probable that the gas is exploiting these differences. However, when gas pressurisation is stopped at day 930 and the pressure held constant, flow into the clay dramatically reduces by around $98.5 \%$, indicating that propagation of the main gas pathway(s) practically cease when the pressure is held constant. The small continuous flux observed following this event may result from the movement of gas along small-scale features which are only present because the bentonite is not fully mature. If correct, these fluxes should reduce in magnitude during later tests as the buffer equilibrates. Given the sudden reduction in flow, it suggests that gas is not flowing

\footnotetext{
${ }^{1}$ The start volume of gas was estimated by fitting the early predicted pressure response to that of the measured values from FL903. The start gas volume for the second test phase was estimated at the end of the test by displacing the remaining gas with water through the FL903 drain vent.
} 
within the original porosity of the clay and that the initial network of gas pathways fails to locate an adequate sink capable of accommodating the small in-flow of gas.

When gas pressurisation is reinstated on day 952, the departure between measured and predicted gas pressure continues almost immediately (Figure 7B), indicating that the previous network of gas pathways continue to extend as soon as the pressure begins to increase. Gas flow into the clay gradually increases with time until day 970, at which point there is a marked increase in flow. This occurs when the gas pressure is marginally greater (approximately $0.2 \mathrm{MPa}$ ) than the local total stress measured on the rock wall, but is marginally smaller (around $0.25 \mathrm{MPa}$ ) than the radial stress measured some distance away on the canister surface at PC903. Axial stress measured at PB902 was also marginally higher than the gas pressure, by around 0.3 MPa. Gas pressure continued to increase reaching a peak pressure of 5.66 MPa at day 972.3. This is followed by a small spontaneous negative transient leading to a quasi steady state at a gas pressure of around 5.5 MPa. Examination of the post peak gas flux exhibits dynamic behaviour (over and undershooting flux into the system) suggestive of unstable gas flow. These observations are qualitatively similar to results reported by Horseman et al. [1999] and Harrington and Horseman [2003] performed on laboratory scale tests.

The injection pump was stopped (i.e. a shut-in test) at day 974 and the gas pressure allowed to decay providing an estimate for the apparent capillary threshold pressure which is tentatively estimated to be around $4.9 \mathrm{MPa}$. This pressure is significantly higher than that required to initiate gas entry but is very similar to the average radial stress measured on the canister which is also close to the axial stress measured locally within the clay at PB902. This result suggests a strong correlation between gas transport and total stress and supports the observations reported by Harrington and Horseman [2003] based on laboratory scale tests. Analysis of the pressure decay curve shows conspicuous breaks in slope indicative of the sealing and temporary formation of highly unstable gas pathways.

Following peak gas pressure a well pronounced increase in radial stress occurs around the entire base of the deposition hole, with the highest increase noted in the vertical plane below the point of injection (Figure 8). This strongly suggests gas preferentially moved downwards, probably along the interface between the canister and buffer. It is notable that the radial stress immediately adjacent to FL903 actually decreases during this time. Analysis of the porewater pressure sensors located within the buffer show no obvious sensitivity to the injection of gas. In contrast, axial stress sensors located beneath and above the canister appear to register the passage of gas. A small inflection in the rate of increase in axial stress at the base of the canister occurs shortly after the peak in gas pressure. Such a reduction in stress can only be caused by the removal of load, suggesting some form of displacement has occurred as a result of gas injection.

\subsubsection{Post gas test hydraulic response}

To examine the effect of gas flow on the hydraulic properties of the buffer, a second hydraulic test was performed. Prior to the start of hydraulic testing, water was injected into the test system to help sweep residual gas from the tubework and filter. Once complete the hydraulic pressure was increased to $4.4 \mathrm{MPa}$ (very close to the original test pressure in Section 4.1.1) and flux into the clay monitored with time. As before, when steady-state conditions were established, hydraulic pressure in the injection system was reduced to $0.48 \mathrm{MPa}$ and the flux into and out of the clay (during the 'recovery' stage) monitored with time. Figure 8 shows the data for this stage compared to that from the previous hydraulic test performed prior to gas injection. While modelling of the post-gas hydraulic data has not been performed due to the uncertainties associated with defining an accurate saturation at the start of the test, a visual inspection of the graph clearly indicates that little, if any, significant 
change in conductivity has occurred as a result of gas injection. The slight offset in the solid grey line is indicative of a small increase in hydraulic storage. Based on this data, the nascent gas pathways appear to have little, if any, effect on the hydraulic performance of the buffer. This is not unexpected given the limited duration of the gas tests and the quantities of helium injected.

\subsection{Phase 2 (day 1430 to date)}

The second stage of artificial hydration began on day 1110. However, this was interrupted on day 1289 by the failure of an air compressor which resulted in the automatic closure of all pneumatic valves. This isolated each of the canister filters from the rest of the test system resulting in an impromptu pressure decay test. Good model fits were achieved to the pressure decay functions for most of the filters [Cuss et al. 2010], which suggests that the transient behaviour can be captured in terms of a single hydraulic transport and storage coefficient. The upper filters generally indicate higher values for hydraulic conductivity and specific storage than elsewhere in the system, ranging from $8.8 \times 10^{-14} \mathrm{~m} / \mathrm{s}$ to $4.9 \times 10^{-13} \mathrm{~m} / \mathrm{s}$. Values obtained for filters FL901, FL902 and FL904 ranged between $7.8 \times 10^{-14} \mathrm{~m} / \mathrm{s}$ and $1.3 \times 10^{-13} \mathrm{~m} / \mathrm{s}$. These values are marginally lower than those presented in Section 4.1.1 indicating little if any significant change in hydraulic baseline properties between the two test stages.

\subsubsection{Baseline hydraulic measurements}

In order to accurately determine the evolution in hydraulic properties around filter FL903 prior to the next phase of preliminary gas testing, a second constant head and pressure recovery test were performed from day 1473 to 1577 . Results from these tests are crossplotted on Figure 6 for comparison. Inspection of the data shows a marked reduction in steady-state flow rate and a reduction in the duration of the transient flow response. Numerical modelling of the data yield estimates for the hydraulic conductivity and specific storage of $5.3 \times 10^{-14} \mathrm{~m} / \mathrm{s}$ and $4.0 \times 10^{-5} \mathrm{~m}^{-1}$ respectively. These values are close to those observed during the first hydraulic tests (Section 4.1.1), suggesting the bentonite is locally saturated around the filter. At the end of the pressure recovery stage, the injection pump was switched off and the pressure allowed to evolve. By the end of the test stage the hydraulic pressure in filter FL903 had increased to around 1.3 MPa.

\subsubsection{Gas injection test}

Following completion of the hydraulic tests on day 1577, the injection system was purged with gas. Contrary to the initial tests described in Section 4.1.2, neon was selected as the test permeant for this phase of testing, to facilitate tracking of the gas through the host rock by future gas sampling of the packered intervals in each of the pressure relief holes (neon is absent from the natural pore waters of Äspö).

Prior to the onset of testing a known volume of neon was introduced into the injection system and the pressure in filter FL903 set to $1.3 \mathrm{MPa}$. Pressure was then held constant for approximately 28 days in order to allow the system to equilibrate while neon moved into solution saturating the hydraulic fluid contained within the injection system.

Gas testing began on day 1606. Pressure within the test system was gradually raised over a 9 day period to the first target value of $2.55 \mathrm{MPa}$, at which point the gas pressure was held constant for a further 15 days while flux into the clay monitored with time (Figure 9A). Analysis of the data indicates a small flux into the clay begins at the onset of pumping, suggesting that the gas entry pressure was close to the start value of $1.3 \mathrm{MPa}$. This is significantly higher than the previous value observed in Section 4.1.2 (0.65 MPa) and is further evidence for the maturation of the clay. Once the injection pump was switched to 
constant pressure mode and the pressure in the filter held constant at $2.55 \mathrm{MPa}$, gas flow into the clay dramatically reduced and continued to decline over the next 15 days, resulting in a small background flux ${ }^{2}$ of around $2.5 \times 10^{-10} \mathrm{~m}^{3} / \mathrm{s}$. This was around $95 \%$ lower than that observed prior to the change in pump mode. The similarity in this response to that from the earlier gas tests described in Section 4.1.2 suggests that the same processes governing the precursor movement of gas remain in operation.

The injection pump was then switched back to constant flow rate mode and the gas pressure gradually increased over a 9 day period to the next target value of $3.8 \mathrm{MPa}$. As before, once the target pressure was reached the pump was switched to constant pressure mode and the pressure held constant for 28.6 days. Inspection of the graph in Figure 8(A) shows qualitatively similar behaviour to that noted above, but, with one significant difference. Figure 9(A) clearly shows that the magnitude of the flux into the clay during the second pressurisation event is conspicuously lower than that during the first step performed at a lower gas pressure. The lack of correlation between the rate of gas flow into the clay and the gas pressure gradient driving the flux cannot be reconciled with classic concepts of two-phase flow.

By the end of the stage, gas flow into the clay had reduced to around $7.2 \times 10^{-11} \mathrm{~m}^{3} / \mathrm{s}$, representing a reduction in flux of approximately $98 \%$ compared to the value prior to the change in pump mode. This value is also significantly lower than that for the previous constant pressure step. These observations will be discussion in Section 5.0.

A third pressure ramp was initiated on day 1674, which gradually increased gas pressure over a 16 day period to the final target value of $5.05 \mathrm{MPa}$. Gas pressure was then held constant and flow into the clay monitored as before. Pressure was held constant for a total of 52 days (from day 1690 to 1742) in order to (i) examine the evolution in gas inflow with time and (ii) to maintain stable conditions near the Lasgit deposition hole in order to minimise its impact on a neighbouring test underway within the Äspö HRL. Inspection of Figure 9(A) exhibits similar behaviour to that noted for the previous two pressure steps. Flux into the clay is again lower than that observed during the first pressurisation event and by the end of the constant pressure stage, gas flow into the clay was negligible at around $1 \times 10^{-12} \mathrm{~m}^{3} / \mathrm{s}$. This is an order of magnitude smaller than the flux observed during the previous constant pressure stage at 3.8 MPa.

The final gas injection stage was initiated on day 1742 with a relatively slow injection rate of $500 \mu \mathrm{l} / \mathrm{h}$. As seen in previous pressure steps, gas flow into the clay began to increase as pressurisation of the gas continued, Figure 9(B). However, it is interesting to note that during the initial stage of this test, flux into the clay is lower than that observed during the previous pressurisation event and exhibits little, if any, sign of pressure dependency with the injection gas pressure. At day 1766.55 gas flow into the buffer spontaneously increases, exhibiting as well defined peak before decreasing to a steady-state value of around $8 \times 10^{-9} \mathrm{~m}^{3} / \mathrm{s}$. Gas pressure continued to increase reaching a maximum value of $5.87 \mathrm{MPa}$ at day 1767.3, 0.21 MPa higher than for the first gas test performed 26 months before. This was followed by a spontaneous negative pressure transient which approaches an asymptote of around 5.55 MPa. Examination of Figure 9(B) indicates the response of the buffer to the ingress of gas during this phase of testing is very similar in form to that observed in the small-scale laboratory experiments reported by Harrington and Horseman [1999, 2003]. Post peak, both flux and pressure data initially "under-shoot" then "over-shoot" the ultimate asymptote value symptomatic of unstable gas pathways [Harrington and Horseman 1999].

At peak gas pressure total stress and porewater pressure sensors indicate gas flow is both localised and a highly complex dynamic process with pathways opening and closing probably

\footnotetext{
${ }^{2}$ All gas fluxes are corrected to STP conditions (defined as $273.15 \mathrm{~K}$ and $101.325 \mathrm{kPa}$ ).
} 
in response to localised changes in gas pressure (Figure 10). Analysis of the data indicates conspicuous kicks in value at and after peak gas pressure, providing strong evidence for the time-dependent evolution of a tortuous network of unstable gas pathways. Figure 11 illustrates this behaviour for a small subset of data. Here borehole intensity plots have been generated showing the response in total stress and porewater pressure prior to and immediately after major gas entry. While this data indicates gas pathways initially propagate downwards and then across and upwards through the clay or clay/rock wall interface, later 'breakthrough' events from different sensor locations (similar in form to that illustrated in Figure 10C) indicate that the gas pathway network continues to evolve, even though the system is at quasi steady-state. This observation closely agrees with data reported by Harrington and Horseman [2003].

\subsection{Discussion}

Results from the hydraulic and gas injection experiments presented in this paper show a consistent pattern of behaviour. Hydraulic data from the three constant head and pressure recovery tests show little, if any, significant decrease in permeability during the course of the test, suggesting the continued maturation of the clay has little impact on the hydraulic properties of the bentonite close to each filter. Good model fits were achieved to the hydraulic pressure decay functions for most of the filters, which suggests that the transient behaviour can be captured in terms of a single hydraulic transport coefficient and a single hydraulic storage coefficient.

While gas entry pressures are much lower than those anticipated for saturated intact bentonite of a similar dry density [Harrington and Horseman 2003], these can be explained by gas exploiting the incomplete hydration state of the buffer and the heterogeneous nature of the stress field within the clay. The increase in gas entry pressure between gas injection experiments is also indicative of the maturation of the clay.

However, the reduction in gas inflow during each constant pressure step prior to major gas entry is difficult to reconcile with standard concepts of two-phase flow [Aziz and Settari, 1979; de Marsily, 1986]. The large reduction in gas flow (ranging from 95-98.5\%) when pressure is held constant (Figure 9A), suggests an apparent reduction in gas permeability of the buffer. While this does not conform to classic concepts of two-phase flow it can be explained by a pathway propagation model. According to Griffith crack theory, a crack will only propagate when the decrease in strain energy just balances the increase in surface energy. In essence, this can be viewed as the slow time-dependent expansion of gas pathway(s), conceptually little different to that of inflating one or more tiny balloons within the bentonite, where the walls of the latter represent the pathway surfaces within the clay. As gas pressure increases the cracks/balloons slowly expand/propagate resulting in a larger network of gas-filled pathways. If gas pressure is held constant, the capacity for further expansion of the cracks/balloons is limited, by both the balance in strain and surface energies and by the availability of inherent weaknesses within the buffer system. The observed reduction in gas inflow rates for the higher constant pressure steps strongly support this line of reasoning and suggests that the availability or interconnectivity of such weaknesses within the clay (from small-scale transient features related to hydraulic/stress disequilibrium) is limited locally around the point of the injection zone.

Given the reduction in gas flow rates at higher pressures, it seems clear from the data that only a limited quantity of gas can be injected into the clay through this mechanism, suggesting that as the buffer hydrates, the capacity for this type of flow will reduce.

The hypothesis for a network of pressure induced pathways is further supported by the lack of correlation between the rate of gas flow into the clay and the gas pressure gradient driving the flux prior to major gas entry, Figure 9A. This observation cannot be easily reconciled 
with classic concepts of two-phase flow and suggests an alternative mechanism, probably pathway dilation, governs gas migration within the Lasgit system.

Major gas entry into the clay is associated with a rapid increase in flux. This is followed by a spontaneous negative pressure transient leading to a quasi steady-state. There is considerable evidence for the existence of a highly-dynamic, tortuous network of pressure induced pathways which evolve both temporally and geospatially within the clay, opening and closing probably due to local changes in gas pressure and or effective stress. The observed couple between major gas entry and total stress is consistent with observations from a field experiment testing the integrity of a borehole seal reported by Van Geet et al. [2007] who observed gas breakthrough pressures close to the measured value of radial stress. It is also consistent with previous small-scale laboratory experiments reported by Harington and Horseman [2003], who observed qualitatively similar behaviour to that noted in this study.

When gas injection is stopped and the pressure allowed to decay (i.e. a shut-in stage) the pressure declines to an asymptotic value close to that of the total stress locally within the deposition hole (4.9 MPa). While this appears contrary to expectation given the low entry pressures discussed above, it strongly indicates that penetration of buffer by significant quantities of gas is only possible when the gas pressure equals or exceeds the local value of stress. The important coupling between gas, stress and porewater pressure at the repository scale is clearly demonstrated by this study. However, the importance of this coupling and the dependency of specific parameters will be investigated in future experiments planned at the Lasgit test site.

\subsection{Conclusions}

The Lasgit experiment has been in continuous operation since February 2005. The first two years focused on the artificial hydration of the bentonite buffer. This was followed by a programme of hydraulic and gas injection tests which ran from day 843 to 1110. A further period of artificial hydration occurred from day 1110 to 1385, followed by a more complex programme of gas injection testing which remains on going (day 1385+).

Modelling of the hydraulic data was undertaken using a 2D axisymmetric variably saturated finite element porewater flow model. Hydraulic conductivity and specific storage values were found to range from $9 \times 10^{-14}$ to $1.6 \times 10^{-13} \mathrm{~m} / \mathrm{s}$ and $5.5 \times 10^{-5}$ to $4.4 \times 10^{-4} \mathrm{~m}^{-1}$ respectively. Filter FL903, subsequently used to inject gas, was modelled using values of $7.5 \times 10^{-14} \mathrm{~m} / \mathrm{s}$ and $2.5 \times 10^{-5} \mathrm{~m}^{-1}$. A second set of hydraulic measurements performed over a year and a half later yielded conductivities and specific storages for the lower filter arrays in the range $7.8 \times 10^{-14} \mathrm{~m} / \mathrm{s}$ and $1.3 \times 10^{-13} \mathrm{~m} / \mathrm{s}$ respectively, with FL903 modelled with values of $5.3 \times 10^{-14}$ $\mathrm{m} / \mathrm{s}$ and $4.0 \times 10^{-5} \mathrm{~m}^{-1}$. Both data sets agree with laboratory data for tests performed on saturated clay and suggest the continued maturation of the clay has little impact on the hydraulic properties of the bentonite close to each filter.

Two gas injection tests were performed over a three year period. During the course of testing, gas entry pressure was found to increase from around $0.65 \mathrm{MPa}$ to approximately $1.3 \mathrm{MPa}$. While these pressures are much lower than those anticipated for saturated intact bentonite of a similar dry density [Harrington and Horseman, 2003], these can be explained by gas exploiting the incomplete hydration state of the buffer and the heterogeneous nature of the stress field within the clay. The increase in gas entry pressure between gas injection experiments is also indicative of the maturation of the clay.

The reduction in gas inflow (ranging from 95-98.5\%) noted during the constant pressure steps prior to major gas entry, is difficult to reconcile with standard concepts of two-phase flow and is suggestive of an apparent reduction in gas permeability for the buffer. The sequential reduction in gas flow rate for each constant pressure step indicates only a limited quantity of gas can be injected into the clay without interacting with the continuum stress field. The lack 
of correlation between the rate of gas inflow and the gas pressure gradient driving the flux prior to major gas entry supports this reasoning. These observations suggest that pathway dilation is the primary mechanism governing gas migration within the Lasgit system.

Major gas entry into the clay is associated with a rapid increase in flux linked to a series of kicks in axial and radial stress and porewater pressure. Peak gas pressure is followed by a well defined negative pressure transient leading to a quasi-steady-state. The post peak gas flux exhibited dynamic behaviour, over and undershooting the flux into the system, which is highly suggestive of unstable gas flow.

When gas injection is stopped, flux into the clay rapidly reduces before entering an extended period of very small flows. This is accompanied by a rapid reduction in pressure which decays to an asymptotic value close to that of the total stress locally within the deposition hole. While this appears contrary to expectation given the low entry pressures, it strongly indicates that penetration of the buffer by significant quantities of gas is only possible when the gas pressure equals or exceeds the local value of stress. Changes in slope of the decay curve provide further evidence for the presence of highly unstable gas pathways.

Hydraulic measurements performed after the initial gas tests yielded comparable results, indicating the nascent gas pathways appear to have little if any effect on the hydraulic performance of the buffer. This is not unexpected given the limited duration of the gas tests and the quantities of helium injected.

Considerable evidence exists for the development of a highly-dynamic, tortuous network of pressure induced pathways which evolve both temporally and geospatially within the clay, opening and closing probably due to local changes in gas pressure and or effective stress. This is consistent with observations from previous experiments in particular those reported by Harrington and Horseman [2003].

Given the incomplete hydration state of the buffer and the heterogeneous nature of the stress field within the clay, it seems probable that the gas is exploiting these differences. As testing continues and the buffer evolves, greater insight into the processes governing the movement of gas within buffer bentonite, under evolving boundary conditions, will occur. Once the current phase of gas testing is complete in 2010, artificial hydration will continue.

The important coupling between gas, stress and porewater pressure at the repository scale is well demonstrated by the Lasgit experiment. The importance and interdependencies related to this coupling will be investigated in future experiments currently planned for the Lasgit experiment.

\subsection{References}

Aziz, K. And Settari, A. (1979). Petroleum Simulation. Applied Science, London

Cuss, R.J., Harrington, J.F. and Noy, D.J. (2010). Large scale gsa injection test (Lasgit) performed at the Aspo Hard Rock Laboratory: Summary report 2008. Report TR-03-02. Svensk Kärbränslehantering AB (SKB), Stockholm, Sweden.

De Marsily, G., 1986, Quantitative hydrogeology for engineers: Academic Press, New York (440p).

Donohew, A.T., Horseman, S.T. and Harrington, J.F. (2000). Gas entry into unconfined clay pastes between the liquid and plastic limits. Chapter 18. In: Environmental Mineralogy Microbial Interactions, Anthropogenic Influences, Contaminated Land and Waste Management (eds J.D. Cotter-Howells, L.S. Campbell, E. Valsami-Jones and M. Batchelder), Mineralogical Society, London, Special Publication No. 9, 369-394. 
Gallé, C. (1998). Migration des gaz et pression de rupture dans une argile compactée destinée à la barrière ouvragée d'un stackage profound. Bulletin Soc. Géol. France, Vol. 169, Part 5, 675-680.

Gallé, C. and Tanai, K. (1998). Evaluation of gas transport properties of backfill materials for waste disposal: $\mathrm{H}_{2}$ migration experiments in compacted Fo-Ca clay. Clays and Clay Minerals, Vol. 46, Part 5, 498-508.

Gray, M., Kirkham, T.J., Lin, A.W.-L., and Graham, J. (1996). On the gas breakthrough resistance of engineered clay barrier materials proposed for use in nuclear fuel waste disposal. In: Proc. CNS Int. Conf. on Deep Disposal of Radioactive Waste, Canadian Nuclear Society, Winnipeg, Manitoba, 16-19 Sept.

Harrington, J.F. and Horseman, S.T. (1999). Gas transport properties of clays and mudrocks. In: Muds And Mudstones: Physical And Fluid Flow Properties (eds A.C.Aplin, A.J. Fleet, and J.H.S. Macquaker). Geological Society of London, Special Publication No. 158, 107-124.

Harrington, J.F. and Horseman, S.T. (2003) Gas migration in KBS-3 buffer bentonite: Sensitivity of test parameters to experimental boundary conditions. Report TR-03-02. Svensk Kärbränslehantering AB (SKB), Stockholm, Sweden.

Horseman, S.T. and Harrington, J.F. (1994). Migration of repository gases in an overconsolidated clay. British Geological Survey, British Geological Survey, Technical report WE/94/7.

Horseman, S.T. (1996). Generation and migration of repository gases: Some key considerations in radioactive waste disposal. In: Proc. Int. 2-Day Conference, London, 21-22 Nov. 1996, IBC Technical Services, Energy Division, 26 pp.

Horseman, S.T., Harrington, J.F. and Sellin, P. (1997). Gas Migration In Mx80 Buffer Bentonite. In: Proc. Scientific Basis For Nuclear Waste Management XX, Boston, 2-6 Dec., 1996 (eds W.J. Gray And I.R. Triay), MRS Symposia Proceedings, Vol. 465, Materials Research Society, Warrendale, Pennsylvania, 1003-1010.

Horseman, S.T., Harrington, J.F. and Sellin, P. (1999). Gas migration in clay barriers. Engineering Geology, Vol. 54, 139-149.

Horseman, S.T., Harrington, J.F. and Sellin, P. (2004) Water and gas flow in Mx80 bentonite buffer clay. In: Symposium on the Scientific Basis for Nuclear Waste Management XXVII (Kalmar), Materials Research Society, Vol. 807. 715-720.

Hume, H.B. (1999). Gas breakthrough in compacted Avonlea bentonite. MSc thesis, Department of Soil Science, University of Manitoba, Winnipeg, Canada.

Huyakorn, P.S., and Pinder, G.F., 1983. Computational methods in subsurface flow. Academic Press, New York.

Ortiz, L., Volcharet, G., De Canniere, P., Aertsens, M., Horseman, S.T., Harrington, J.F., Impey, M., and Einchcomb, S. (1997). MEGAS - Modelling and Experiments on Gas Migration in Repository Host-rocks. Proc. EU PEGASUS Meeting at Rapolina-Terme, Italy, 14-15 June 1995. Nuclear Science and Technology Series, EUR 16746 EN, Luxembourg, 127-147. 
Pusch, R., Ranhagen, L. and Nilsson, K. (1985). Gas migration through Mx-80 bentonite. Nagra Technical Report NTB 85-36, Wettingen, Switzerland.

Pusch, R., Hökmark, H. and Börgesson, L. (1987). Outline of models of water and gas flow through smectite clay buffers. SKB Technical Report 87-10, Stockholm, Sweden.

Rodwell, W.R., Harris, A.W., Horseman, S.T., Lalieux, P., Müller, M., Ortiz Amaya, L. and Pruess, K. (1999). Gas migration and two-phase flow through engineered and geological barriers for a deep repository for radioactive waste. EC/NEA Status Report EUR 19122EN, European Union, Luxembourg.

Sellin, P. and Harrington, J.F. (2006). Large-Scale Gas Injection Test (Lasgit) Current Status. American Nuclear Society High Level Waste Meeting, Las Vegas.

SKB (2009) Design premises for a KBS-3V repository based on results from the safety assessment SR-Can and some subsequent analyses. Technical Report TR-09-22. Svensk Kärnbränslehantering AB (SKB), Stockholm, Sweden.

Tanai, K., Kanno, T. and Gallé, C. (1997). Experimental study of gas permeabilities and breakthrough pressures in clays. In: Scientific Basis For Nuclear Waste Management XX, Boston (eds W.J. Gray And I.R. Triay), MRS Symposia Proceeding Vol. 465, Materials Research Society, Warrendale, Pennsylvania, 1003-1010.

van Genuchten, M.Th., 1980. A closed-form equation for predicting the hydraulic conductivity of unsaturated soils. Soil Sci. Soc. Amer. J., 44, 892-898.

Van Geet, M., Volckaert, G., Bastiaens, W., Maes, N., Weeetjens, E., Sillen, X., Vallejan, B., Gens, A. (2007). Efficiency of a borehole seal by means of pre-compacted bentonite blocks. Physics and Chemistry of the Earth, 32, 123-134.

\subsection{Acknowledgement}

This study was undertaken by staff from the British Geological Survey (Radioactive Waste Team). Funding for the study was provided by SKB (Stockholm), the British Geological Survey and the European Commission through the EURATOM $6^{\text {th }}$ and $7^{\text {th }}$ framework programmes. The authors would like to thank SKB colleagues at the Äspö Hard Rock Laboratory for their help in the set-up, maintenance and operation of the Lasgit experiment, and colleagues at Clay Technology AB who were responsible for the original installation of the Geokon instrumentation and buffer clay. The authors would also like to thank Carljohan Hardenby and Jan Lundin of SwedPower AB for the fracture mapping of the deposition hole, this work is summarised in Cuss et al. (2010). This paper is published with the permission of the Executive Director, British Geological Survey (NERC). 


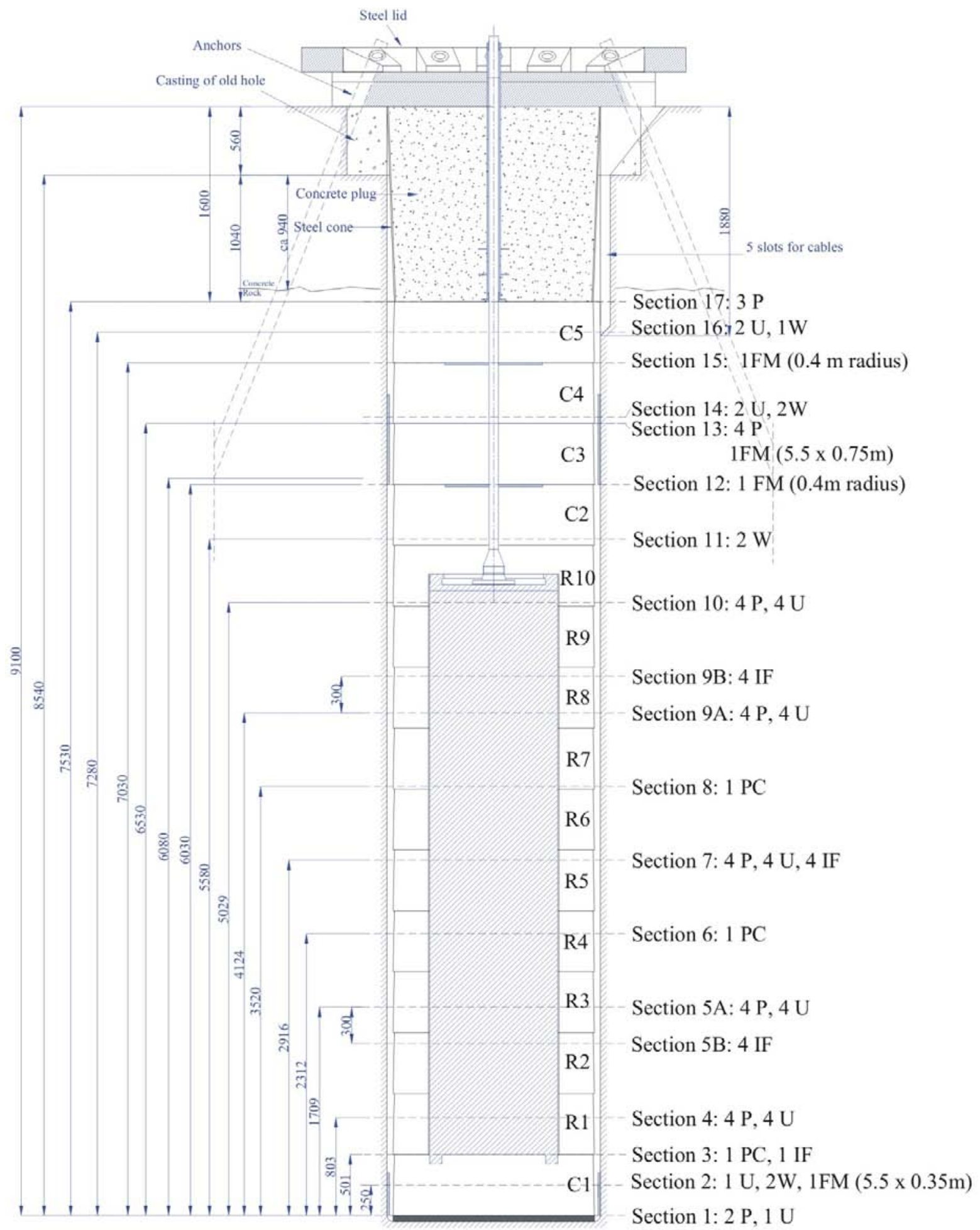

Figure 1 Schematic representation of borehole infrastructure. Sensors are placed in 14 measuring sections, filter mats for artificial water saturation in 4 sections and gas injection filters in 4 sections $(\mathrm{P}=$ total pressure cell, $\mathrm{U}=$ pore pressure cell, $\mathrm{W}=$ relative humidity sensor, $\mathrm{PC}=$ total pressure on canister, $\mathrm{FM}=$ filter mats and IF = injection filters). 


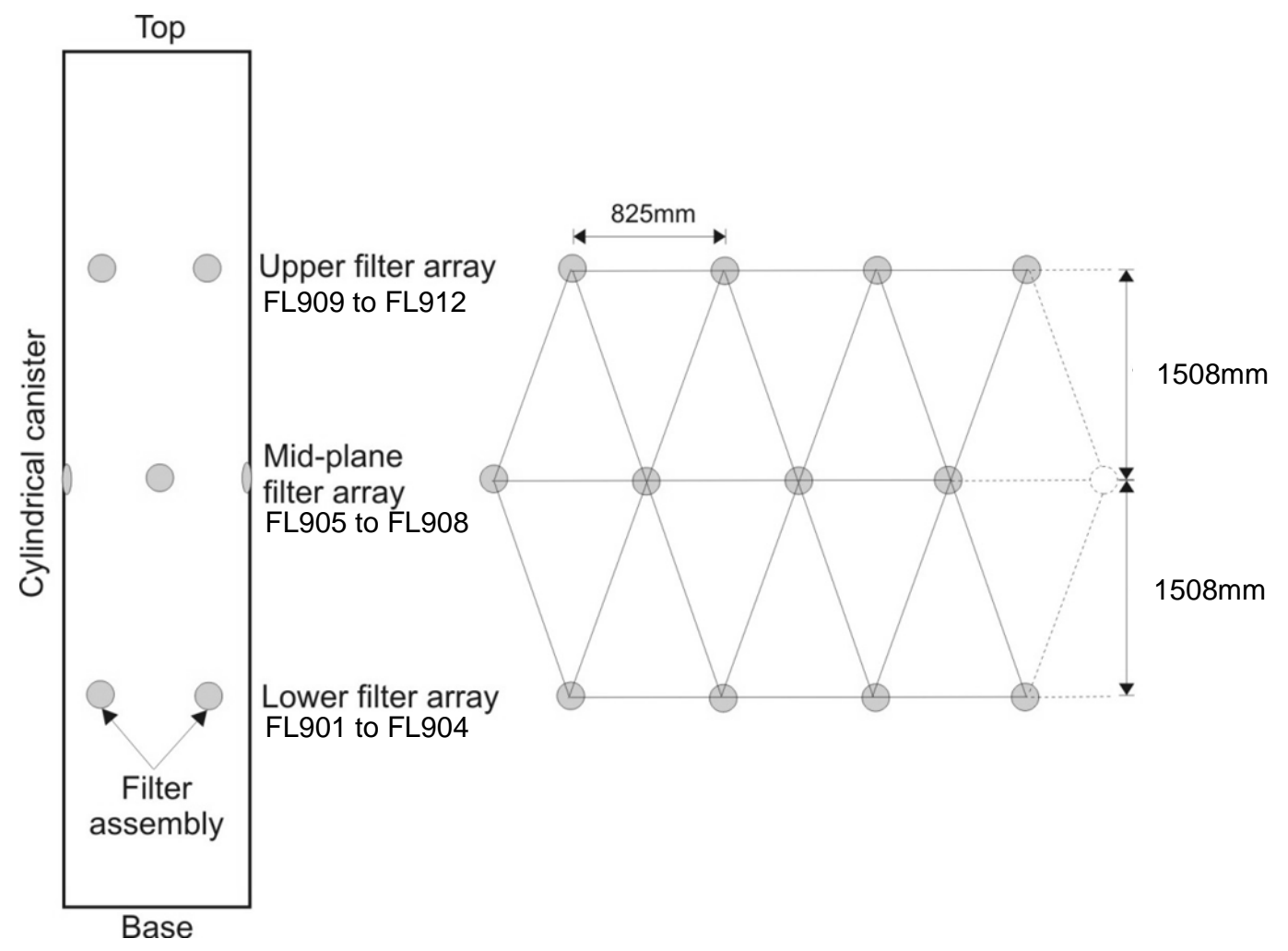

Figure 2 Schematic side view of canister and visible filters (shown in grey). The second graphic is a $2 \mathrm{D}$ representation showing the relative positions of the 12 radial injection filters.

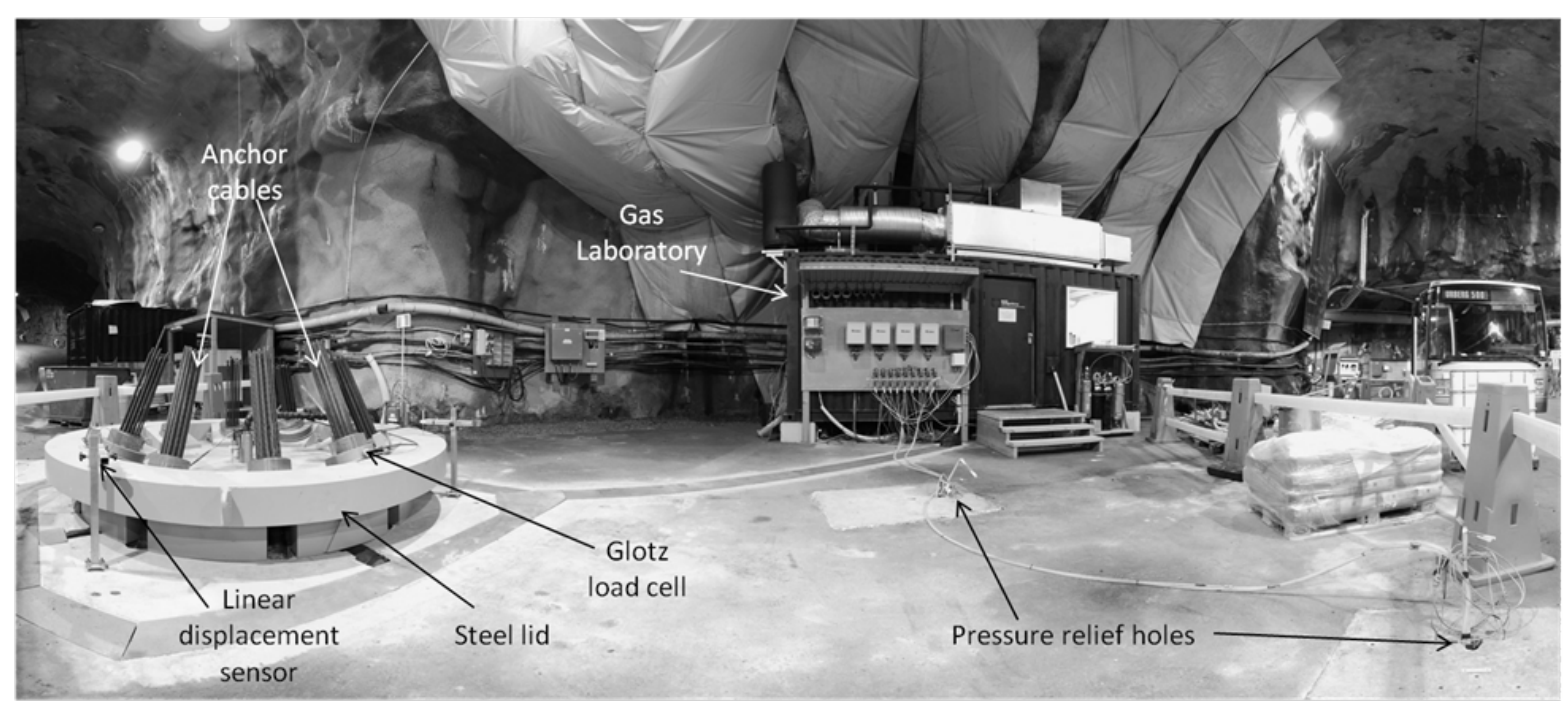

Figure 3 A panoramic view of the Lasgit test site located $420 \mathrm{~m}$ below ground at the Äspö Hard Rock Laboratory in Sweden. The photo shows the position of the deposition hole, gas laboratory, pressure relief holes (containing a series of packered intervals in order to monitor porewater pressure in the surrounding fracture network) and some of the instrumentation attached to the steel lid. 


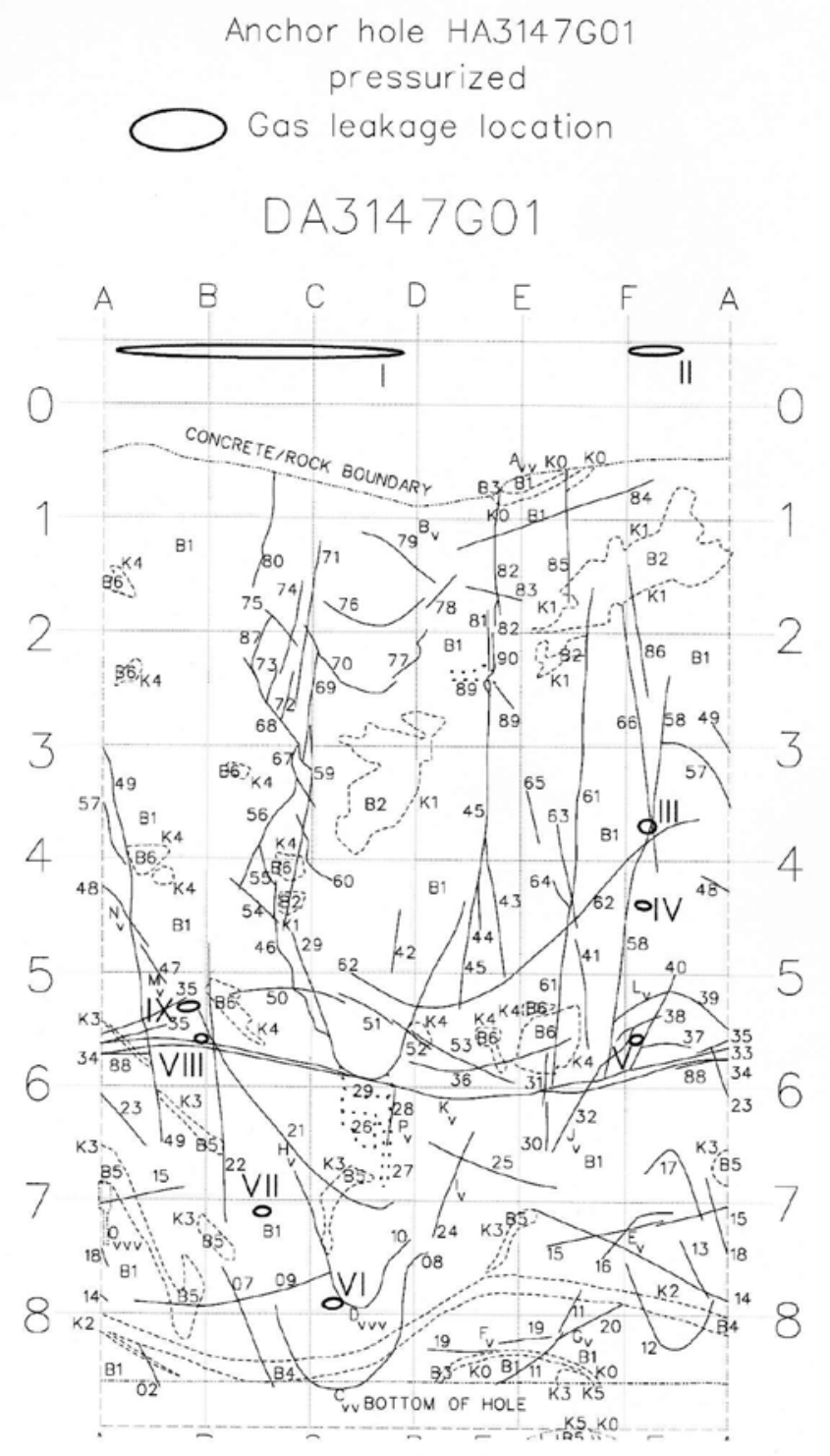

Figure 4 Geological mapping of the deposition hole DA3147G01. Legend: Rock types: B1 = Äspö diorite, greyish and medium-grained with feldspar megacrysts; B2 = greenstone xenolith, black and fine-grained, includes some B1 and B4; B3 = "fine-grained" granite, greyish red and medium-grained; B4 = pegmatite, red and coarse-grained; B5 = "fine-grained" granite - hybrid of B1 and B3, greyish red and medium grained; B6 = greenstone xenolith, black and fine-grained. Contacts: $\mathrm{K} 0-\mathrm{K} 5$ and dashed line; $\mathrm{K} 0=$ contact between B1 and B3; K1 = contact between B1 and B2; K2 = contact between B1 and B4; K3 = contact between B1 and B5; K4 = contact between B1 and B6; K5 = contact between B5 and B3. Fractures: 01-90 and continuous line (thick lines represent water bearing fractures). Water: A-Q and $\mathrm{v}=$ damp-minor seepage, occasional drops; $\mathrm{vv}=$ wet-seepage, drops or minor flow; $\mathrm{vvv}=$ flow. Gas leakage locations when anchor hole HA3147G01 was pressurized are also shown: I. Bubbles on the surface; II. Some bubbles on the surface; III V. Bubbles from one spot; VI. Bubbles; VII. Some bubbles, one spot; VIII. Bubbles, one spot, top of slot; IX. Bubbles from three spots in a row. 


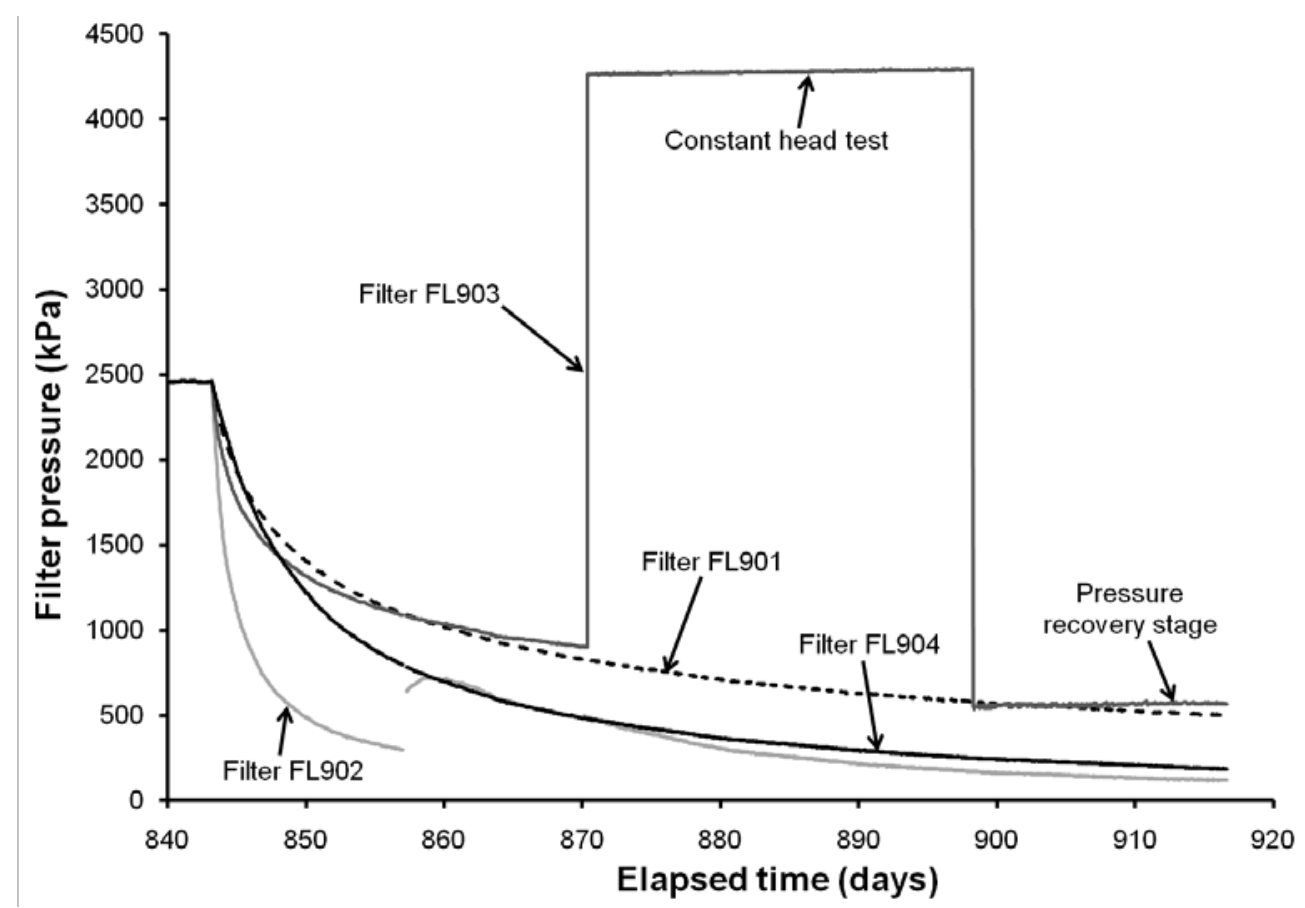

Figure 5 Pressures observed at the lower canister filters FL901 to FL904 during hydraulic testing from day 870 to 917 . The constant head test performed in FL903 is clearly visible as is an unexplained jump in the pressure trace for filter FL902 at around day 857.

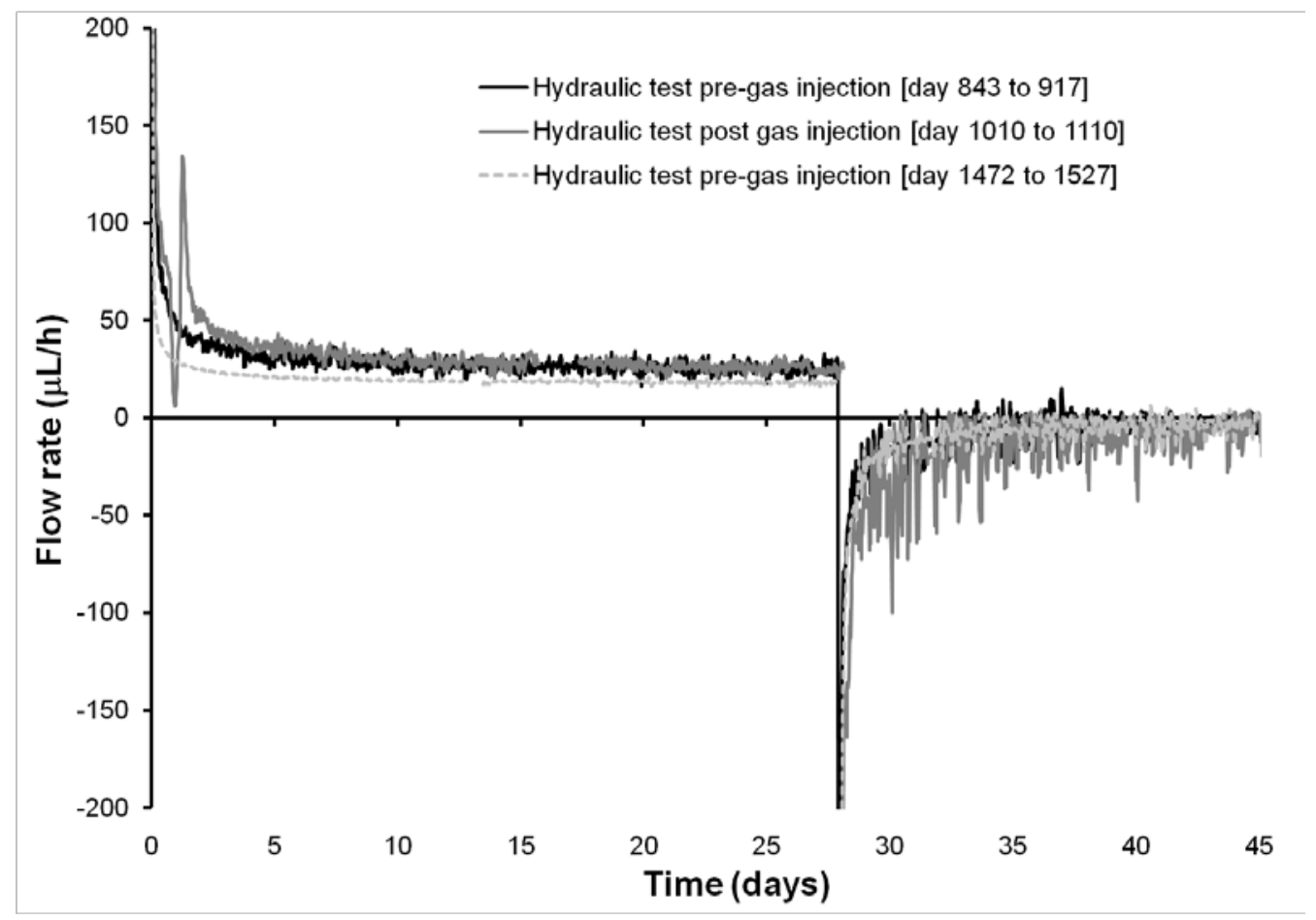

Figure 6 Evolution in flow rate during hydraulic testing. The hydraulic response of the clay to the constant head and recovery stages for both Phase 1 and Phase 2 of testing are shown. The data clearly indicates that the injection of gas during Phase 1 has no significant affect on the hydraulic conductivity of the clay. The reduction in flux (dotted line) indicates a small reduction in conductivity of the clay around filter FL903 following the second phase of the hydration. 

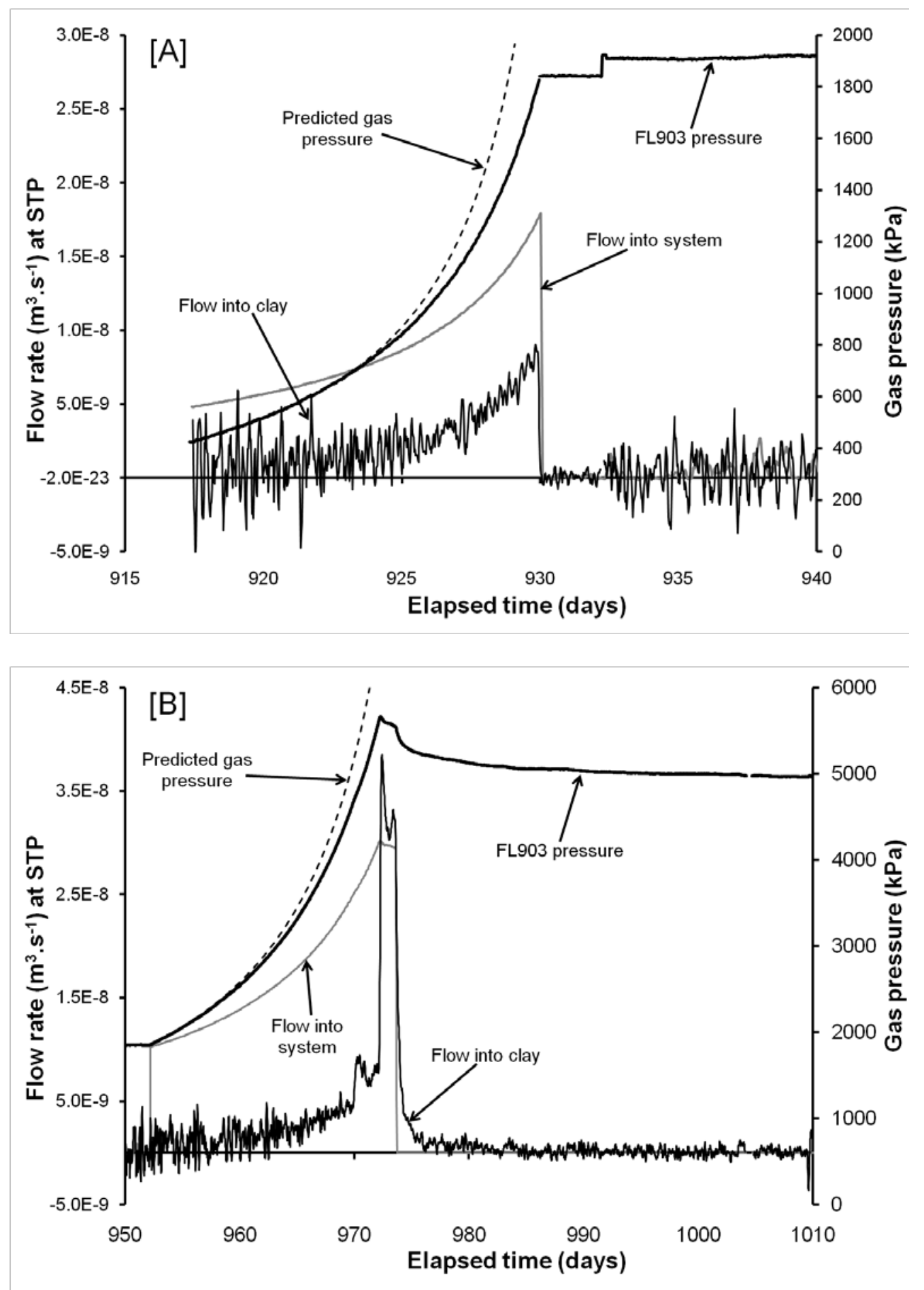

Figure 7 Plots [A] and [B] show the entire injection history for Phase 1 of gas testing. STP flow rates into the injection system and the clay as well as measured and predicted gas pressures are plotted against elapsed time. Flow into the clay is calculated using a combination of weighted moving average and time moving average (mean). For plot [A] the departure between measured and predicted gas pressure is symptomatic of gas penetration of the buffer. In plot [B] the peak pressure response is symptomatic of the development of 'major' gas pathways within the buffer and is qualitatively similar in response to small-scale experiments reported by Horseman and Harrington [2004]. 

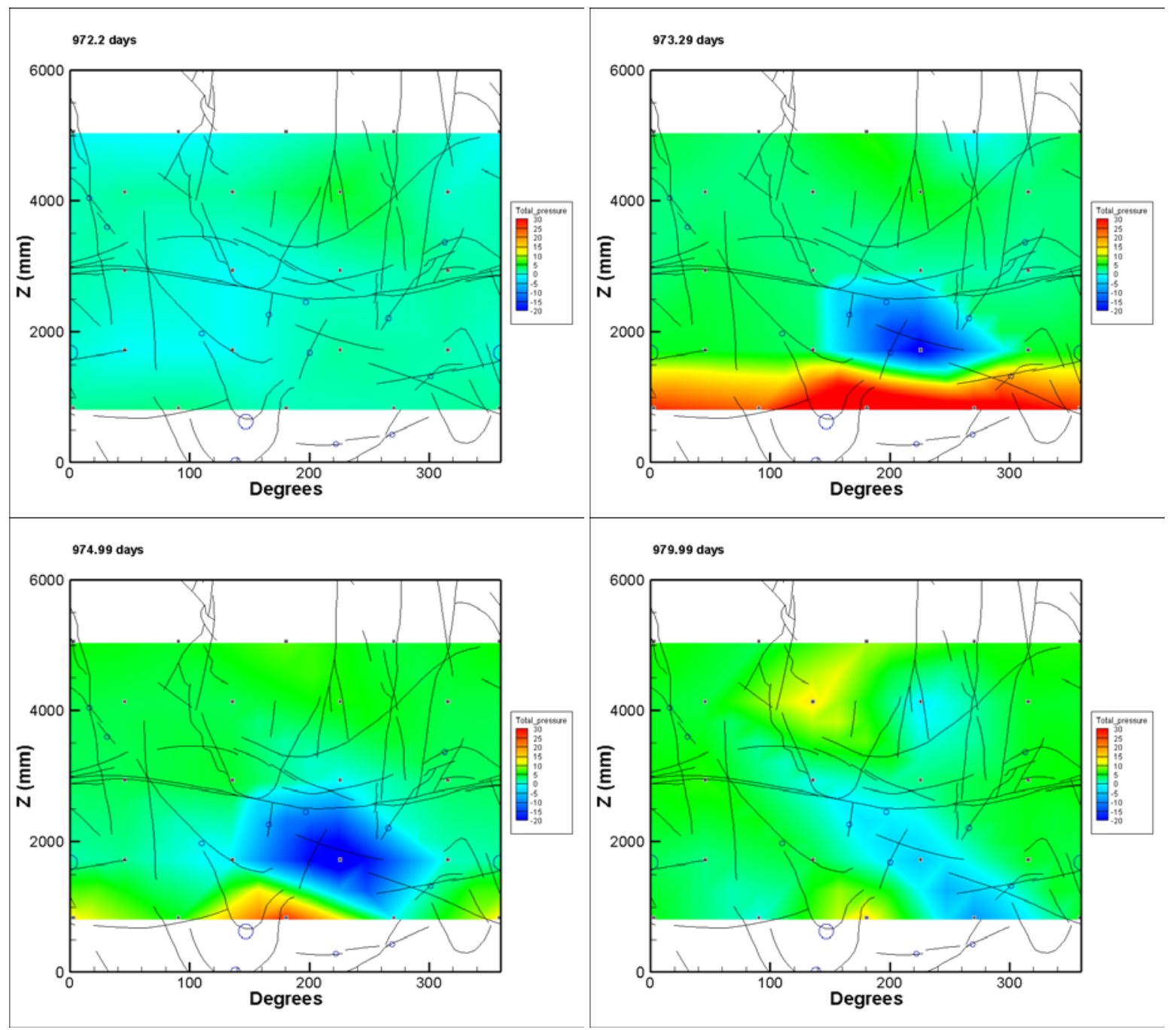

Figure 8 Evolution in normalised radial stress around the deposition hole wall prior to and after the peak in gas pressure (days 972.2 to 979.99). The intensity plots indicate a general increase in radial stress around the base of the deposition hole as gas moves into the clay. Adjacent to the filter radial stresses appear to decline momentarily. The fracture map shown in Figure 4 is displayed on each intensity plot. 

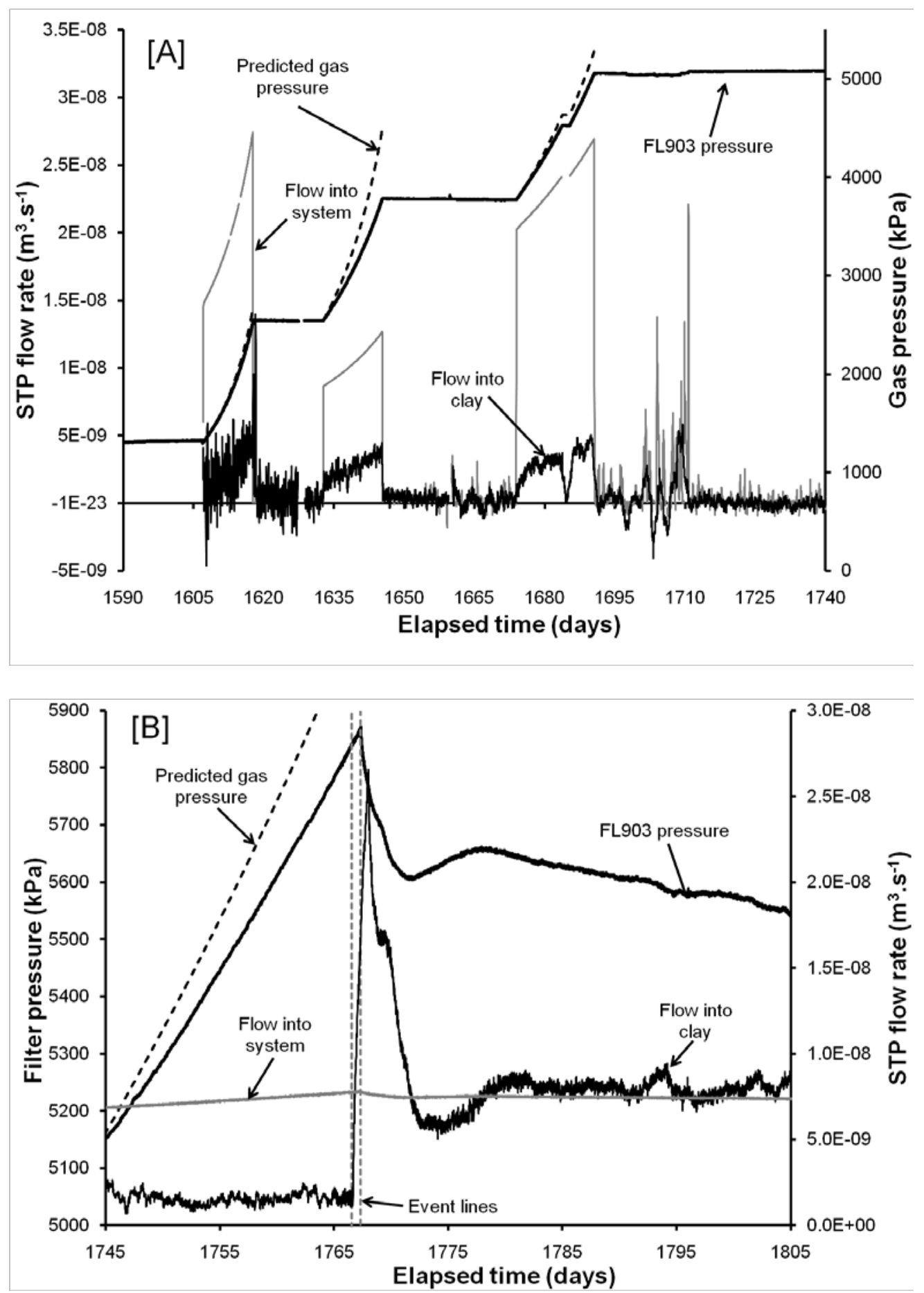

Figure 9 Plots [A] and [B] show the entire injection history for Phase 2 of gas testing. STP flow rates into the injection system and the clay as well as measured and predicted gas pressures are plotted against elapsed time. Inspection of plot [A] shows the reduction in flux into the clay during each constant pressure step. The noise in the data between 1700 and 1715 stems from refilling the injection system with a second pre-charge of neon gas. Plot [B] shows the 'major' gas entry event signified by the rapid increase in flux into the clay. This is followed by a well defined negative flux transient which first under- and then over-shoots the injection flow rate into the system. This is symptomatic of unstable gas pathways. 

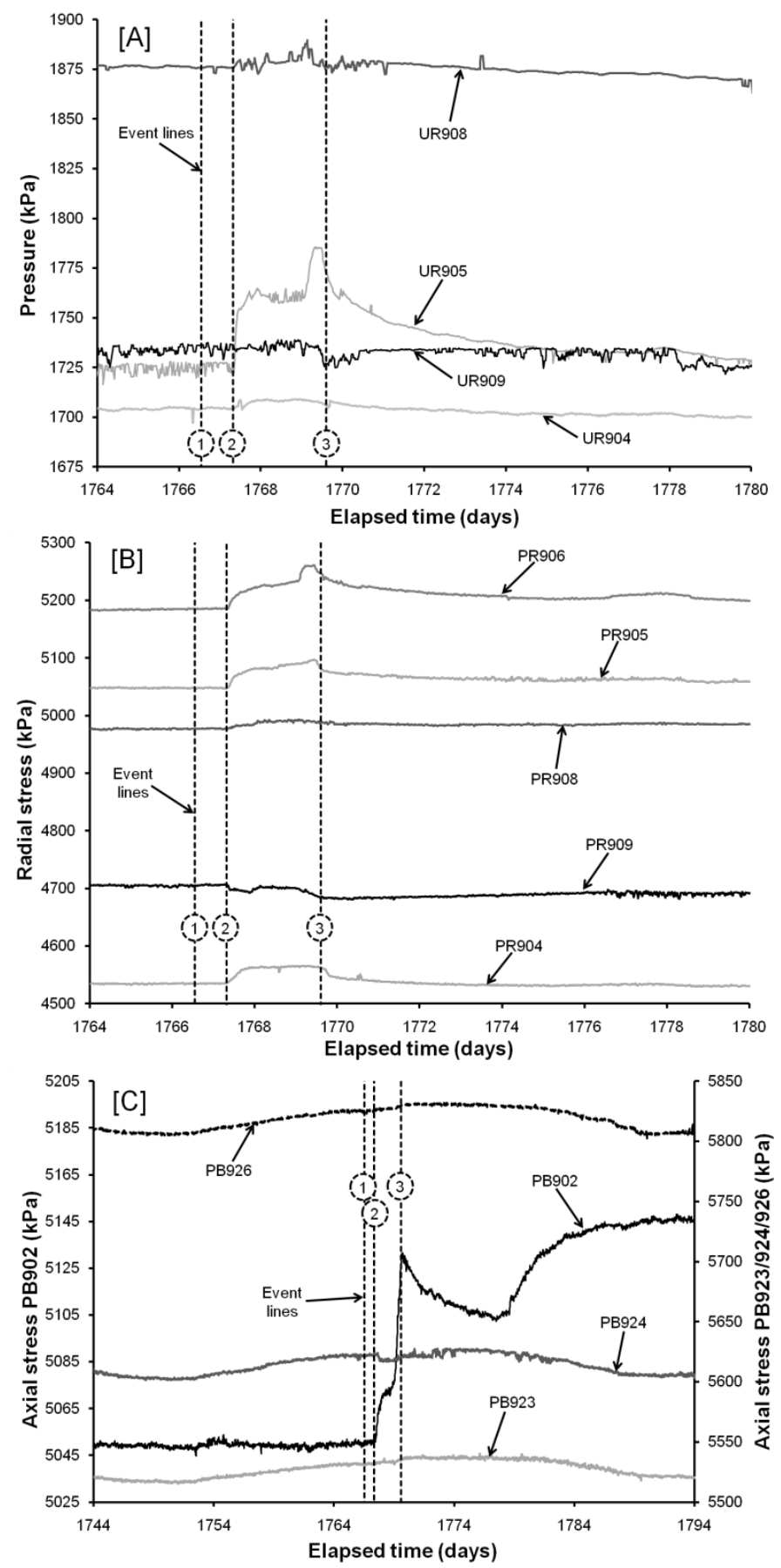

Figure 10 data from borehole instrumentation before and after major gas entry at day 1766.55. Figure 10[A] shows a well-defined response from porewater pressure sensor UR905. The absence of a kick in neighbouring sensors suggests localised pathway flow. Figure 10[B] shows a clear link between changes in radial stress and peak gas pressure. The strength of these responses is related to the geometry and spatial distribution of pathways within the buffer. Figure 10[C] shows the output for a number of axial stress sensors. The output from sensor PB902 shows a series of breakthrough events where total stress spontaneously increases/decreases with time. This provides strong evidence for a highly complex gas pathway network which evolves temporally and geospatially. Event (1) is the start of the major gas flow event, (2) is the peak in gas pressure, and (3) is the peak seen in PB902. 

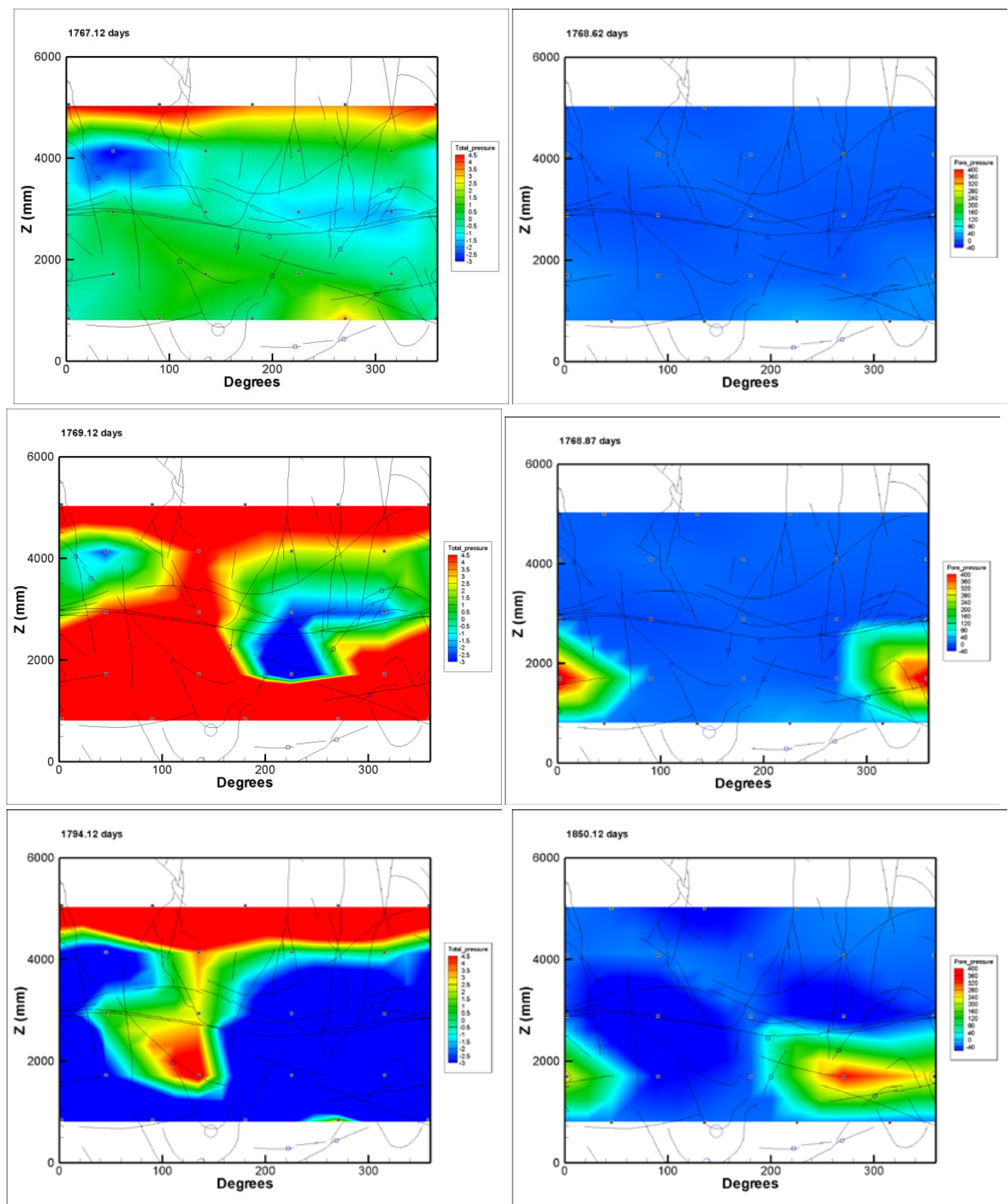

Figure 11 Evolution in normalised radial stress and porewater pressure before, during and after major gas entry at day 1766.7. The left hand column shows the evolution in radial stress, with pressure rapidly increasing (propagating from the base of the plots upwards) as gas penetration of the buffer continues to evolve. The right hand column shows a similar set of intensity plots for porewater pressure. Here, the increase in porewater pressure appears more localised with a strong increase in pressure observed towards the base of the deposition hole. The fracture map shown in Figure 4 is displayed on each intensity plot. 